\title{
A Note on Transliteration and Measurement Units
}

PERSONAL NAMES in the main text are rendered per common usage in English-language publications (e.g., Boris Yeltsin, not Boris El'cin, as the transliteration from Russian would render it); names of companies are rendered per their names on their official websites. (Thus, it is possible that a person's name may be spelled differently in the text and the bibliographic reference.) Bibliographic sources in Russian and Ukrainian were transliterated from the Cyrillic script using the online tools for transliteration (e.g., https://www .translitteration.com/transliteration/en/ukrainian/iso-9/and https:// www.translitteration.com/transliteration/en/russian/iso-9/), which make it possible for the reader desiring to go back to an original source to easily produce the correct Cyrillic form, something that is not currently available in the traditional Library of Congress system. In bibliographic references, the name of the city where the item was published is not transliterated but is simply translated into its common English name; the name of the publishing house is transliterated. All measurement units are metric unless otherwise noted. 
